\title{
Highly Selective Catalytic Reduction of Nitro- to Azoarenes under Ambient Conditions
}

\author{
Carlos G. Morales-Guio • Igor Yuranov • \\ Lioubov Kiwi-Minsker
}

Published online: 3 September 2014

(c) Springer Science+Business Media New York 2014

\begin{abstract}
Catalytic system of Au nanoparticles supported on metal oxides has been developed to produce azoarenes in one-step directly from nitroarenes under mild conditions $\left(30{ }^{\circ} \mathrm{C}, 1\right.$ bar of $\left.\mathrm{N}_{2}\right)$ using 2-propanol as solvent and reducing agent. Close to $100 \%$ chemoselectivity to substituted azoarenes with different functional groups left intact and close to quantitative yields make this procedure promising for the production of azoarenes.
\end{abstract}

Keywords Nitroarenes - Azoarenes - Au supported catalyst $\cdot$ Chemoselectivity $\cdot \mathrm{H}_{2}$-free reduction

\section{Introduction}

New processes that provide quantitative transformation of raw materials to products and minimize the use of energy are the main objectives of today research efforts.

Azoarenes are high value chemicals with wide applications as dyes and pigments, food additives, radical reaction initiators, pharmaceuticals and light-responsive functional materials [1-7]. Among industrial colorants, azo-dyes are by far the most important class, accounting for over $50 \%$ of all commercial dyes [2-4]. A variety of methods have been developed for their production as summarized in recent reviews $[1,5]$. The majority of existing protocols are not catalytic, like the classical diazocoupling reaction that involves stoichiometric amounts of

C. G. Morales-Guio · I. Yuranov · L. Kiwi-Minsker ( $\square)$ Institut des sciences et ingénierie chimiques, Ecole polytechnique fédérale de Lausanne (EPFL), CH H3 594, Station 6, 1015 Lausanne, Switzerland

e-mail: lioubov.kiwi-minsker@epfl.ch toxic nitrous acid and generates equivalent amounts of inorganic salt waste [7-10].

Recent developments in catalysis have opened a door to the more sustainable production of azoarenes through the catalytic oxidation of anilines [11-13] and reduction of nitroarenes [14-16]. Grirrane et al. first reported a novel two-step, one-pot catalytic method for the production of symmetric azoarenes [11, 12] (Fig. 1, reaction 1). The authors oxidized by molecular oxygen expensive aniline derivatives, which in turn could be produced by catalytic hydrogenation of nitroarenes using the same supported $\mathrm{Au}$ catalyst [17]. Hu et al. [14] synthesized azoarenes from nitroaromatics by $\mathrm{H}_{2}$ reduction $\left(P_{\mathrm{H} 2}=1 \mathrm{bar}\right.$, $\mathrm{T}=80-120^{\circ} \mathrm{C}$ ) over unsupported Pt and Pd [15] catalysts (Fig. 1, reaction 2). Zhu et al. [18] reported that azocompounds can be produced with a high yield (up to $99 \%$ ) directly from nitroarenes by photo-catalytic reduction under visible or ultraviolet light using $\mathrm{Au}$ nanoparticles (NPs) supported on $\mathrm{ZrO}_{2}$ at ambient temperature and pressure (Fig. 1, reaction 3).

Despite such remarkable achievements in catalytic synthesis of azoarenes, the stepwise processing, elevated temperatures, or use of light irradiation present practical limitations.

Therefore, we aimed at the development of a catalytic system to produce selectively azo-compounds in one-step under mild conditions. Although the use of alcohols for hydrogen transfer reactions was reported several decades ago [19], their use for the reduction of nitroarenes is still rare. Recently, Ru-NPs supported on non-activated charcoal (Fig. 1, reaction 4) [16] and Au-NPs supported on mesoporous ceria [20] were reported as novel catalytic systems to produce azo-, azoxy- and/or aminoarenes from the corresponding nitroarenes using alcohols as reducing agents. However, low selectivity and slow kinetics even at 


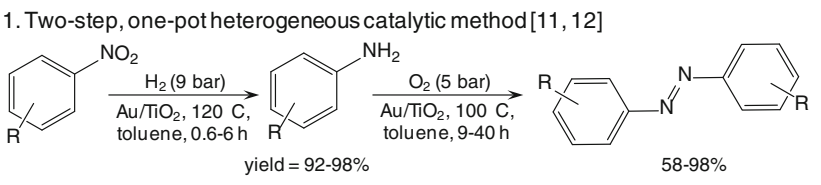

2. Catalytic transformation over unsupported Pt nanowires $[14,15]$

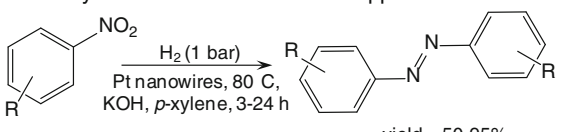

yield $=50-95 \%$

3. Heterogeneous photocatalytic method [18]

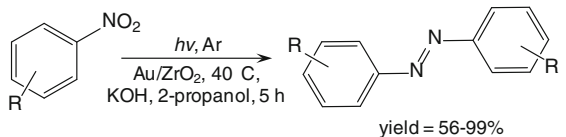

4. Catalytic transformation over supported Ru nanoparticles [16]

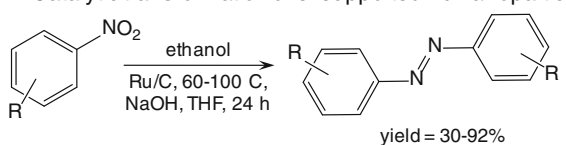

Fig. 1 State-of-the-art catalytic methods of azoarenes synthesis

high temperatures are still important issues that need to be addressed. Thus, the development of valuable alternatives for the one-step production of azoarenes remains of fundamental and industrial importance.

Herein we report a direct and highly chemoselective catalytic transformation of a wide range of substituted nitroarenes to azoarenes using 2-propanol as solvent and the reducing agent at the same time. A typical reaction was carried out at $30{ }^{\circ} \mathrm{C}$ in a 2-propanol solution of $\mathrm{KOH}$ and nitroarene in the presence of Au-based catalyst under $\mathrm{N}_{2}$ flow. Such a simple procedure under ambient pressure and low temperature renders selectively the azoarenes, tolerating a large number of substituents in the aromatic ring such as -halo, $-\mathrm{OCH}_{3}$ and vinyl groups. The catalysts have been characterized via atomic absorption spectroscopy (AAS), high resolution transmission electron microscopy (HRTEM), powder X-ray diffraction (XRD), and X-ray photo-electron spectroscopy (XPS).

\section{Experimental Section}

\subsection{Reagents}

Commercial $1.0 \%$ gold on titanium dioxide extrudates $\left(\mathrm{Au} / \mathrm{TiO}_{2}\right.$, AUROlite $\left.{ }^{\mathrm{TM}}\right), 1.0 \%$ gold on aluminum oxide extrudates $\left(\mathrm{Au} / \mathrm{Al}_{2} \mathrm{O}_{3}\right.$, AUROlite $\left.{ }^{\mathrm{TM}}\right), 1.0 \%$ gold on zinc oxide granulate $\left(\mathrm{Au} / \mathrm{ZnO}\right.$, AUROlite $\left.{ }^{\mathrm{TM}}\right)$ were bought from STREM Chemical Inc., whereas $1.0 \%$ platinum on gamma alumina powder reduced $\left(1.0 \% \mathrm{Pt} / \mathrm{Al}_{2} \mathrm{O}_{3}\right)$ was bought from ABCR Gmbh \& Co. $5.0 \%$ palladium on aluminum oxide $\left(5.0 \% \mathrm{Pd} / \mathrm{Al}_{2} \mathrm{O}_{3}\right)$ was acquired from STREM
Chemical Inc. $5.0 \%$ copper on aluminum oxide $(5.0 \%$ $\mathrm{Cu} / \mathrm{Al}_{2} \mathrm{O}_{3}$ ) was home made by impregnation of $\mathrm{Al}_{2} \mathrm{O}_{3}$ by an aqueous solution of $\mathrm{Cu}$ (II) nitrate followed by drying and reduction by $\mathrm{H}_{2}$.

All the reactants used in this study are commercially available from Aldrich, Alfa Aesar, Acros Organic.

\section{$2.2 \mathrm{Au} / \mathrm{HT}$ Catalyst Preparation}

The $\mathrm{Mg}-\mathrm{Al}$ hydrotalcite $\left(\mathrm{HT}, \mathrm{Mg}_{6} \mathrm{Al}_{2}(\mathrm{OH})_{16} \mathrm{CO}_{3}\right.$ ) support synthesis was carried out by a well-known co-precipitation procedure [21]. The $1.3 \% \mathrm{Au} / \mathrm{HT}$ catalyst was synthesized by deposition of gold precursor $\mathrm{HAuCl}_{4}$ (ABCR Gmbh \& Co., $49 \% \mathrm{Au}$ ) on the synthesized HT support. The yellow slurry obtained after stirring $(8 \mathrm{~h})$ of the support $(2 \mathrm{~g})$ in an aqueous $\mathrm{HAuCl}_{4}$ solution $(1.3 \mathrm{M}, 50 \mathrm{ml})$ was filtered, washed with deionized water, and dried at $30{ }^{\circ} \mathrm{C}$ under vacuum. Subsequent $\mathrm{Au}^{3+}$ reduction was performed in 2-propanol $(50 \mathrm{~mL})$ at $80{ }^{\circ} \mathrm{C}(2 \mathrm{~h})$ under nitrogen flow $\left(100 \mathrm{~mL} \mathrm{~min}^{-1}\right)$. The resulting solid Au/HT was filtered, washed thoroughly by water and dried at $30{ }^{\circ} \mathrm{C}$ under vacuum.

\subsection{Characterization}

The Au content in the synthesized catalyst was measured by AAS using a Shimadzu AA-6650 spectrometer with an air-acetylene flame from the diluted solutions in "aqua regia" (1/3 v/v $\left.\mathrm{HNO}_{3} / \mathrm{HCl}\right)$. Powder X-ray diffractograms were recorded on a Bruker/Siemens D500 incident X-ray diffractometer ( $\mathrm{Cu} \mathrm{K} \alpha$ radiation). HR-TEM was performed using a JEOL JEM-3011 high-resolution transmission electron microscope operated at an accelerating voltage of $300 \mathrm{kV}$. The detailed analysis of particle morphology was done using Gatan Digital Micrograph 3.6.5. The specimens were prepared by droplet coating of $\mathrm{MeOH}$ suspensions on carbon coated Ni grids (Agar Scientific, 300 mesh). NMR spectra were recorded on a Bruker Avance III $400 \mathrm{MHz}$ spectrometer at room temperature using $\mathrm{CDCl}_{3}$ as solvent. Chemical shifts are reported relative to the residual proton or carbon signal of the solvent. XPS spectra were measured on a Kratos Axis Ultra DLD XPS System using a dual AlMg X-ray anode with a circular spatial resolution of $15 \mu \mathrm{m}$. Samples were prepared by droplet coating of the methanol dispersed catalyst particles on Si wafers.

\subsection{Hydrogenation Reaction}

All catalytic experiments were carried out in a stirred round-bottom flask heated at $30{ }^{\circ} \mathrm{C}$ containing a solution of $\mathrm{KOH}(0.5 \mathrm{mmol})$ in 2-propanol $(25 \mathrm{~mL})$, aromatic nitroarene $(1.5 \mathrm{mmol})$ and $n$-dodecane as an internal standard. The amount of the base was previously optimized in order 
Table 1 Catalytic reduction of nitro- to azobenzene over supported catalysts

\begin{tabular}{|c|c|c|c|c|c|c|c|}
\hline $1 \mathrm{a}$ & & & $3 a$ & & & & \\
\hline \multirow[t]{2}{*}{ Entry } & \multirow[t]{2}{*}{ Catalyst } & \multirow[t]{2}{*}{$t(\mathrm{~h})$} & \multicolumn{3}{|c|}{ Yield $(\%)^{\mathrm{a}}$} & \multirow[t]{2}{*}{ Conv. $(\%)^{\mathrm{a}}$} & \multirow[t]{2}{*}{ Sel. 3a $(\%)^{\mathrm{a}}$} \\
\hline & & & $2 a$ & $3 \mathbf{a}$ & $4 a$ & & \\
\hline 1 & - & 8.0 & 2 & 2 & 10 & 14 & 14 \\
\hline 2 & $1.3 \% \mathrm{Au} / \mathrm{HT}$ & 2.5 & 0 & $>99$ & 0 & 100 & $>99$ \\
\hline $3^{\mathrm{b}}$ & $1.3 \% \mathrm{Au} / \mathrm{HT}$ & 3.1 & 0 & $>99$ & 0 & 100 & $>99$ \\
\hline $4^{\mathrm{c}}$ & $1.3 \% \mathrm{Au} / \mathrm{HT}$ & 0.5 & 3 & 95 & 2 & 100 & 95 \\
\hline 5 & $1.0 \% \mathrm{Au} / \mathrm{TiO}_{2}$ & 3.0 & 1 & 99 & 0 & 100 & 99 \\
\hline 6 & $1.0 \% \mathrm{Au} / \mathrm{Al}_{2} \mathrm{O}_{3}$ & 3.5 & 1 & 95 & 1 & 99 & 96 \\
\hline 7 & $1.0 \% \mathrm{Au} / \mathrm{ZnO}$ & 7.5 & 0 & $>99$ & 0 & 100 & $>99$ \\
\hline $8^{\mathrm{c}}$ & $1.0 \% \mathrm{Pt} / \mathrm{Al}_{2} \mathrm{O}_{3}$ & 3.5 & 0 & 0 & 0 & $<1$ & 0 \\
\hline $9^{c}$ & $5.0 \% \mathrm{Pd} / \mathrm{Al}_{2} \mathrm{O}_{3}$ & 8.0 & 14 & 8 & 44 & 75 & 12 \\
\hline $10^{\mathrm{c}}$ & $5.0 \% \mathrm{Cu} / \mathrm{Al}_{2} \mathrm{O}_{3}$ & 3.0 & 0 & 0 & 2 & 2 & 0 \\
\hline
\end{tabular}

Reaction conditions: catalyst (M: $1.0 \mathrm{~mol} \%), \mathbf{1 a}(1.5 \mathrm{mmol}), \mathrm{KOH}(0.5 \mathrm{mmol}), 2$-propanol $(25 \mathrm{~mL}), \mathrm{N}_{2}$ flow $(100 \mathrm{~mL} / \mathrm{min}, \mathrm{STP})$ at $30{ }^{\circ} \mathrm{C}$

a Determined by GC using $n$-dodecane as internal standard

b 2nd Catalyst reuse

c $65^{\circ}$

to increase selectivity towards the desired azoarenes. After 15 min of stirring under $\mathrm{N}_{2}$ flow, the catalyst containing $1 \mathrm{~mol} \%$ of metal in respect to a nitroarene was quickly added to the solution. The flask was closed and kept under a $\mathrm{N}_{2}$ flow until the end of the reaction. Small samples $(<0.2 \mathrm{~mL})$ were taken periodically during the reaction and analyzed using a gas chromatography (Perkin-Elmer Auto System XL equipped with a programmed split/splitless injector and a flame ionization detector, employing a DB-1 capillary column (i.d. $=0.33 \mathrm{~mm}$, length $=30 \mathrm{~m}$, film thickness $=0.20 \mu \mathrm{m}$ ) or TLC.

After the reaction, the mixture was immediately filtered. Toluene was used to wash the solid catalyst and to extract the products. The filtrate was neutralized with an aqueous solution of $\mathrm{HCl}$. Subsequently, after phase separation the solvent was evaporated and an orange powder was re-dissolved in toluene. The organic phase was washed three times with distilled water. The final solvent evaporation gave an aromatic azo-compound as orange crystals.

\section{Results and Discussion}

Selective transformation of nitrobenzene 1a to azobenzene 3a (Table 1, entries 2-7) was achieved using both the commercially available $\mathrm{Au}^{0}$-NPs $\left(d_{a v}\right.$. $\left.3 \mathrm{~nm}\right)$ heterogeneous catalysts $\left(\mathrm{Au} / \mathrm{TiO}_{2}, \mathrm{Au} / \mathrm{Al}_{2} \mathrm{O}_{3}, \mathrm{Au} / \mathrm{ZnO}\right)$ [22-24] and home-made $\mathrm{Au}^{0}$-NPs supported on $\mathrm{Mg}-\mathrm{Al}$ hydrotalcite $(\mathrm{Au} / \mathrm{HT})$. It is worth to note that without catalyst and/or base only a negligible conversion of 1a was detected (Table 1, entry 1$)$. The smallest $\operatorname{Au}^{0}$-NPs $\left(d_{a v}\right.$. $\left.2.4 \mathrm{~nm}\right)$ supported on basic HT (Fig. 2) demonstrated the shortest time to attain a full conversion of nitrobenzene indicating the highest activity (Table 1 , entry 2 ). The catalyst reuse ( 2 times) after its filtration and washing showed some decrease in catalytic activity without noticeable change in chemoselectivity (Table 1, entry 3). TEM measurements (not shown) confirmed that the $\mathrm{Au}^{0}$-NP size distribution did not change after the recycling. No gold was found in the resulting liquid phase (Atomic Absorption Spectroscopy analysis) confirming the absence of Au leaching.

The reaction time over $\mathrm{Au} / \mathrm{HT}$ can be reduced from 2.5 to $0.5 \mathrm{~h}$ maintaining high selectivity towards $3 \mathbf{a}(\sim 95 \%)$ by increasing the reaction temperature up to $65^{\circ} \mathrm{C}$ (Table 1, entry 4).

At higher temperatures, 3a undergoes over-hydrogenation to aniline $\mathbf{2 a}$. The transformation of nitro- to azobenzene was followed by GC analysis over the reaction time. It was found that nitrobenzene was first reduced to azoxybenzene and then to azobenzene (Fig. 3). The mass balance was consistently above $98 \%$ indicating that azoxybenzene was the only detectable reaction intermediate.

Other metals ( $\mathrm{Pt}, \mathrm{Pd}, \mathrm{Cu})$ known to be active in the reduction of nitroarenes were also tested showing very low activities with poor selectivity (Table 1, entries 8-10).

It was found that the 1a conversion of less than $40 \%$ could be attained if the reaction was conducted in a static $\mathrm{N}_{2}$ atmosphere. Moreover, no reaction was observed if 

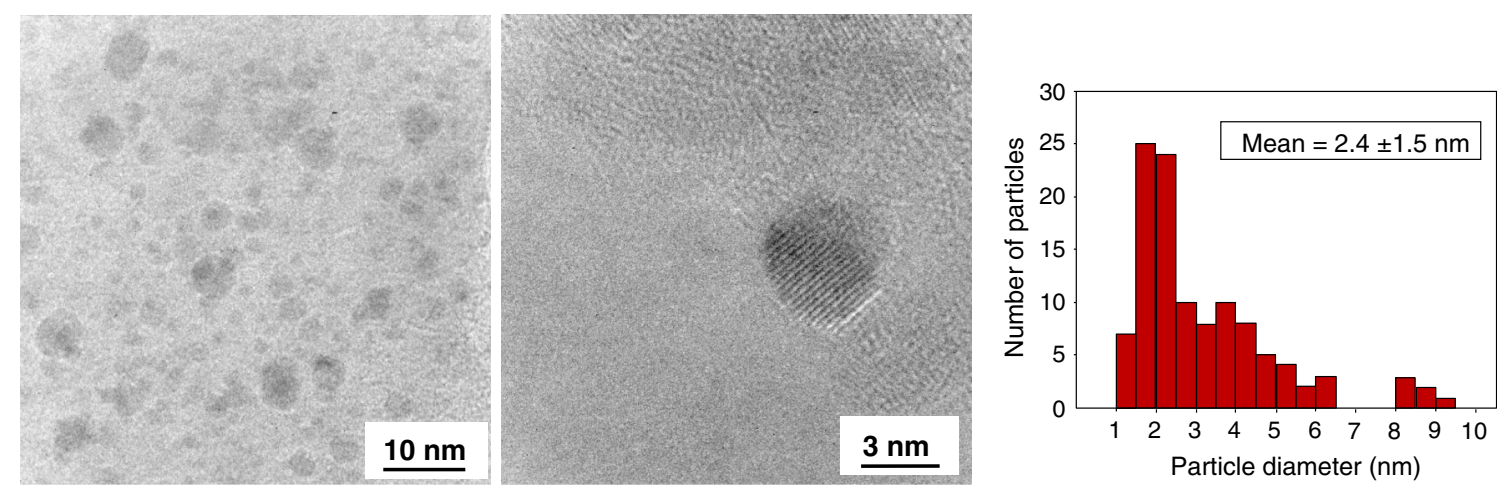

Fig. $21.3 \%$ Au/HT: TEM images and particle size distribution

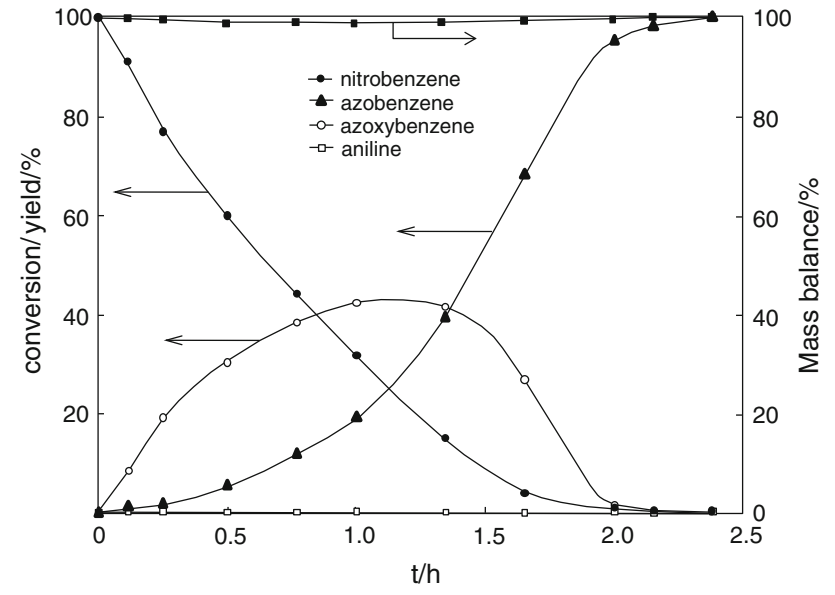

Fig. 3 Reduction of nitrobenzene at $30{ }^{\circ} \mathrm{C}$ over $\mathrm{Au} / \mathrm{HT}$ catalyst in 2-propanol

acetone $(10 \mathrm{vol} \%)$ was added to the initial reaction mixture. Therefore, it was suggested that acetone produced from i-PrOH during the reaction inhibits strongly the hydrogen transfer. In order to avoid the inhibition, the $\mathrm{N}_{2}$ flow was kept through the experiments.

Although the detailed mechanism of transfer hydrogenation of nitrobenezene over $\mathrm{Au}$ - supported catalysts is unknown, the formation of intermediate hydride species $[\mathrm{Au}-\mathrm{H}]$ on the $\mathrm{Au}^{0}-\mathrm{NP}$ surface during the hydrogen transfer from 2-propanol (hydrogen source) to nitrobenzene has been proposed $[18,25]$. A basic site of the support abstracts $\mathrm{H}^{+}$from hydroxyl group of 2-propanol followed by $\beta$-hydride transfer to $\mathrm{Au}^{0}-\mathrm{NP}$ thus forming $[\mathrm{Au}-\mathrm{H}]^{-}$ hydride species $[26,27]$. The Au-hydride and $\mathrm{H}^{+}$seem to be responsible for the nitrobenzene hydrogenation reaction. It is obvious that the smallest $\mathrm{Au}^{0}$-NPs supported on a strongly basic HT can provide more active sites on the interface between $\mathrm{Au}^{0}$-NPs and the support resulting in a higher catalytic activity. Due to a basic environment, the reaction is channeled preferentially into the condensation route (formation of $\mathbf{3 a}$ and $\mathbf{4 a}$, see Table 1) of the reaction network proposed by Haber for the reduction of nitroaromatics [28].

A special run was carried out in the dark using the Au/ HT catalyst in order to verify a possible contribution of photocatalysis. The same catalyst activity was observed irrespectively of day-light irradiation. This finding contradicts the results reported by Zhu et al. [18] for the reductive coupling of nitroarenes over Au supported on $\mathrm{ZrO}_{2}$ under similar reaction conditions. The authors claimed that the reaction was driven exclusively by light and only a negligible reduction of nitrobenezene occurred over the $\mathrm{Au} /$ $\mathrm{ZrO}_{2}$ catalyst in the dark. Moreover, the catalytic effect was attributed to a surface plasmon resonance effect that requires $\mathrm{Au}$ nanoparticles of a 5-8 nm diameter. Our experiments showed that smaller $\mathrm{Au}$ nanoparticles $(2-3 \mathrm{~nm})$ are superior catalysts under both dark and daylight conditions.

Using optimum reaction conditions for the $\mathrm{Au} / \mathrm{HT}$ and commercial $\mathrm{Au} / \mathrm{TiO}_{2}$ catalysts, the synthesis of a range of substituted azoarenes was examined. The results presented in Table 2 demonstrate that the protocol can be successfully employed regardless of the presence of electron donating (1d and e) or withdrawing substituents (1b). In the latter case, the reaction of transfer hydrogenation was observed to be much slower. It is worth noting that, in contrast to nitro-substrates and azoxy-intermediates, most of azo-products are less soluble in 2-propanol. Once formed, they precipitate preventing further over-hydrogenation. Remarkably, the reductive coupling of nitrostyrene $\mathbf{1 e}$ gives quantitatively $4,4^{\prime}$-divinylazobenzene $\mathbf{3 e}$ which is of great industrial importance for the production of photo mobile polymer materials and azobenzene polymers [6, 7].

Asymmetric azoarenes are of great importance as fine chemicals. Conventionally, the synthesis of asymmetric azoarenes proceeds through the azo coupling, Mills or Wallach reactions [1]. In the case of the azo coupling, the diazonium salts used are unstable and thus strict control over the reaction temperature is necessary. In the Mills and 
Table 2 Catalytic synthesis of substituted azoarenes

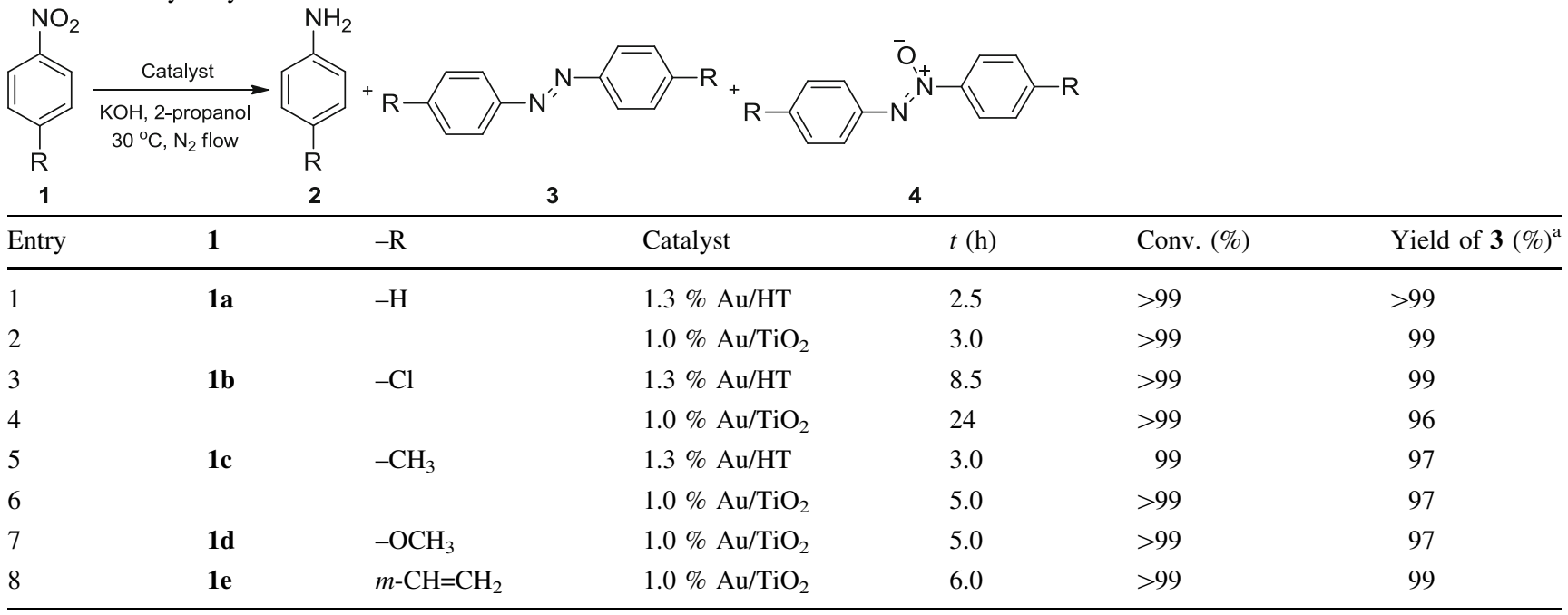

Reaction conditions: catalyst (Au: $1.0 \mathrm{~mol} \%)$, nitroarene $(1.5 \mathrm{mmol}), \mathrm{KOH}(0.5 \mathrm{mmol}), 2$-propanol $(25 \mathrm{~mL}), \mathrm{N}_{2}$ flow $(100 \mathrm{~mL} / \mathrm{min}, \mathrm{STP})$ at $30{ }^{\circ} \mathrm{C}$

a Yield of isolated product

Table 3 Direct synthesis of asymmetrical azoarenes over $\mathrm{Au} / \mathrm{TiO}_{2}$

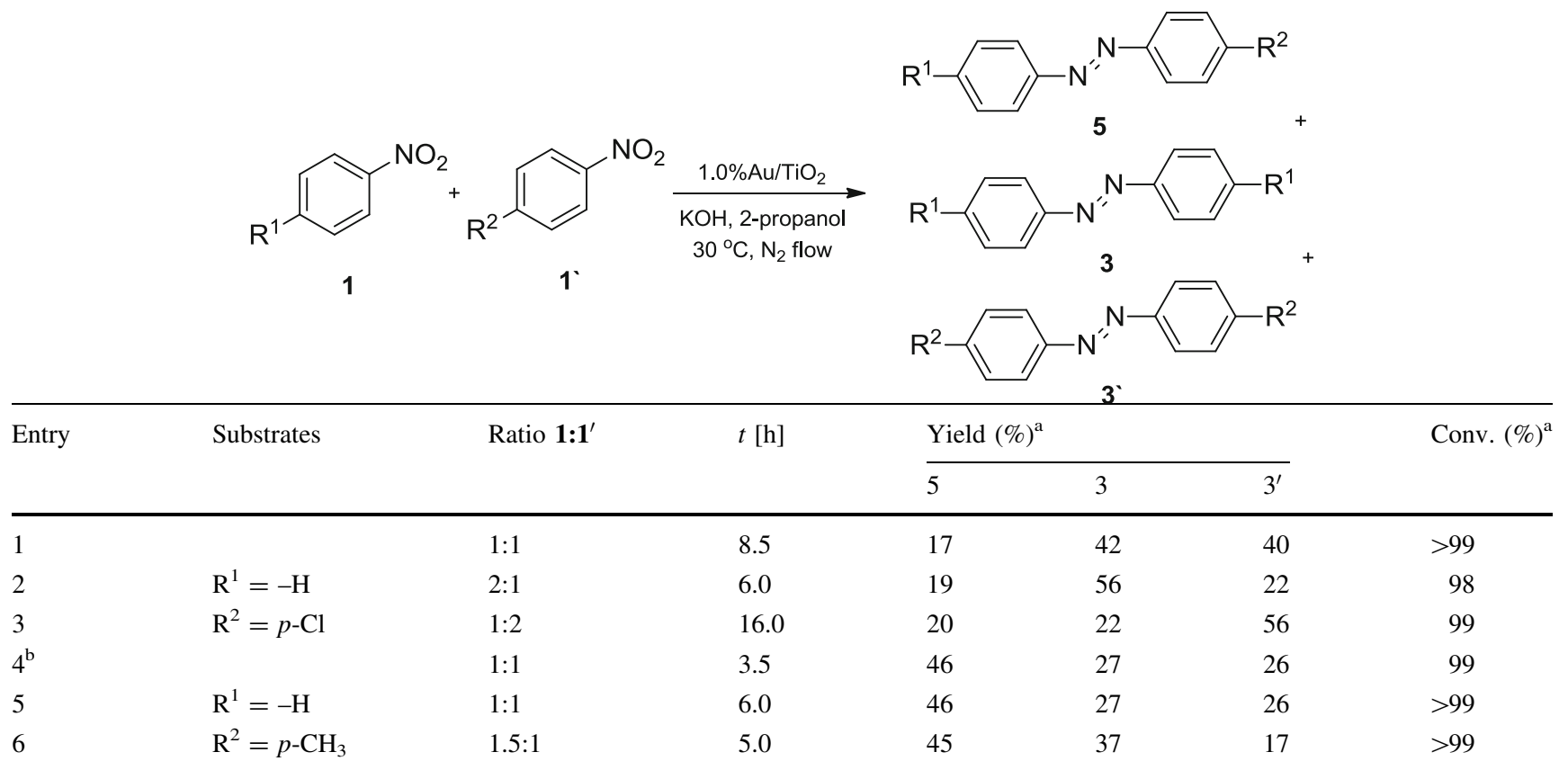

Reaction conditions: catalyst (Au: $1.0 \mathrm{~mol} \%), \mathbf{1}(1.5 \mathrm{mmol}), \mathrm{KOH}(0.5 \mathrm{mmol}), 2$-propanol $(25 \mathrm{~mL}), \mathrm{N}_{2}$ flow $(100 \mathrm{~mL} / \mathrm{min}, \mathrm{STP})$ at $30{ }^{\circ} \mathrm{C}$

${ }^{a}$ Determined by GC using $n$-dodecane as internal standard

${ }^{b}$ Reaction at $50{ }^{\circ} \mathrm{C}$ with $\mathbf{1}^{\prime}$ dosed drop-wise over $1.5 \mathrm{~h}$

Wallach reactions, the synthesis of nitroso- and azoxybenzenes requires the use of oxidants or reducing reagents in stoichiometric or excess amounts and generates undesirable amounts of waste. Only a few attempts to synthesize catalytically asymmetric azoarenes directly from a mixture of two nitroarenes have been reported in the open literature until now $[14,20]$.

Herein, we report an Au-based heterogeneous catalytic system for $\mathrm{H}_{2}$-free synthesis of asymmetrical aromatic azocompounds directly from a mixture of corresponding 
nitroarenes. Two asymmetrical azoarenes were synthesized with fair yields (Table 3 ). The cross coupling of nitroarenes with similar substituents (i.e. nitrobenzene and $p$ nitrotoluene, Table 3, entries 5-6) proceeds easily under the standard reaction conditions. In this case, the rates of consumption of the two substrates were observed to be close and the yield of an asymmetrical product does not depend on the initial molar ratio of the substrates.

In the case of nitroarenes with substituents of different nature (i.e. nitrobenzene and $p$-chloronitrobenzene), the substrates were observed to be consumed in succession. Nitrobenzene started to react only after the complete consumption of $p$-chloronitrobenzene, suggesting a much stronger adsorption of the latter on Au active sites. As a consequence, the yield of the asymmetrical azo-product was found to be low $\sim 20 \%$, independently of the initial molar ratio of the substrates (Table 3, entries 1-3). In order to increase the yield of the target product, the reaction procedure was modified. In this case, at the beginning of the experiment only nitrobenzene was in the reaction mixture. $p$-Chloronitrobenzene was added to the mixture drop-wise during the first $1.5 \mathrm{~h}$ of the reaction maintaining its low instantaneous concentration. As a result, the yield of the asymmetrical azoarene increased more than 2.5-fold (Table 3, entries 4). These promising results open a new catalytic pathway for the catalytic production of asymmetric azo-compounds that circumvents the necessity to prepare anilines, diazonium salts, nitroso-derivatives or azoxy-compounds.

\section{Conclusions}

We have developed $\mathrm{Au}^{0}$-NPs based catalytic system to produce azoarenes in one-step directly from nitroarenes under mild, $\mathrm{H}_{2}$-free conditions using 2-propanol as solvent and reducing agent. The unique chemoselectivity over a range of functional groups (substituents), which did not undergo any transformation under reaction conditions and close to quantitative yields make this procedure promising for the production of symmetrical azoarenes.

The possibility to synthesize asymmetrical azoarenes directly from a mixture of corresponding nitroarenes was also demonstrated.

\subsection{Analytical ${ }^{1} \mathrm{H}$ and ${ }^{13} \mathrm{C}$ NMR data}

azobenzene (Table 1, entry 2):

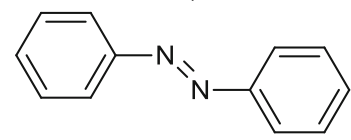

${ }^{1} \mathrm{H}$ NMR $\left(400 \mathrm{MHz}, \mathrm{CDCl}_{3}\right): \delta=7.96-7.94(\mathrm{~d}, 4 \mathrm{H})$, 7.56-7.47 (m, 6H);

${ }^{13} \mathrm{C}$ NMR $\left(100 \mathrm{MHz}, \mathrm{CDCl}_{3}\right): \delta=122.98,129.22$, 131.11, 152.79 .

\subsubsection{1,2-bis(4-chlorophenyl)diazene (Table 2, entry 4)}<smiles>Clc1ccc(/N=N/c2ccc(Cl)cc2)cc1</smiles>

${ }^{1} \mathrm{H}$ NMR $\left(400 \mathrm{MHz}, \mathrm{CDCl}_{3}\right): \delta=7.88-7.85(\mathrm{~d}, 4 \mathrm{H})$, 7.50-7.48 (d, 4H);

${ }^{13} \mathrm{C}$ NMR $\left(100 \mathrm{MHz}, \mathrm{CDCl}_{3}\right): \delta=124.34,129.56$, $137.39,150.96$.

\subsubsection{1,2-dip-tolyldiazene (Table 2, entry 6)}<smiles>Cc1ccc(/N=N/c2ccc(C)cc2)cc1</smiles>

${ }^{1} \mathrm{H}$ NMR $\left(400 \mathrm{MHz}, \mathrm{CDCl}_{3}\right): \delta=7.84-7.82(\mathrm{~d}, 4 \mathrm{H})$, 7.33-7.31 (d, 4H), 2.44 (s, 6H);

${ }^{13} \mathrm{C}$ NMR $\left(100 \mathrm{MHz}, \mathrm{CDCl}_{3}\right): \delta=21.63,122.86$, $129.85,141.34,150.98$.

\subsubsection{1,2-bis(4-methoxyphenyl)diazene (Table 2, entry 7)}

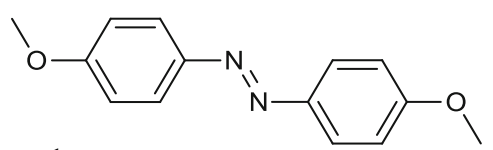

${ }^{1} \mathrm{H}$ NMR $\left(400 \mathrm{MHz}, \mathrm{CDCl}_{3}\right): \delta=7.90-7.88(\mathrm{~d}, 4 \mathrm{H})$, 7.02-6.99 (d, 4H), $3.88(\mathrm{~s}, 6 \mathrm{H})$;

${ }^{13} \mathrm{C}$ NMR $\left(100 \mathrm{MHz}, \mathrm{CDCl}_{3}\right): \delta=55.68,114.29$, 124.47, 147.21, 161.69 .

\subsubsection{4,4'-divinylazobenzene (Table 2, entry 8)}

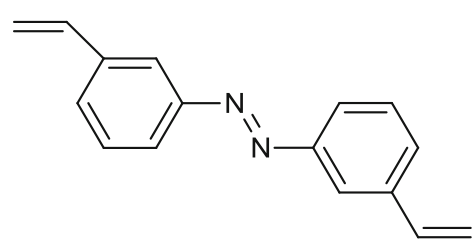

${ }^{1} \mathrm{H}$ NMR (400 MHz, $\mathrm{CDCl}_{3}$ ): $\delta=7.99$ (pseudo-s, 2H), 7.85-7.83 (d, 2H), 7.55-7.47 (m, 4H), 6.86-6.84 (d, 1H), $6.82-6.79(\mathrm{~d}, 1 \mathrm{H}), 5.92-5.88(\mathrm{~d}, 2 \mathrm{H}), 5.38-5.35(\mathrm{~d}, 2 \mathrm{H})$;

${ }^{13} \mathrm{C}$ NMR $\left(100 \mathrm{MHz}, \mathrm{CDCl}_{3}\right): \delta=115.20,120.71$, $122.30,128.92,129.36,136.32,138.77,152.99$.

Acknowledgments The authors thank P. Abdulkin (University of Cambridge) for the participation in catalyst characterization and I. Cornu (EPFL, Lausanne) for the participation in experimental work. The financial support from the Swiss national Science Foundation is highly appreciated. 


\section{References}

1. Merino E (2011) Chem Soc Rev 40:3835-3853

2. Hunger K (2003) Industrial dyes: chemistry, properties applications. Wiley-VCH, Weinheim

3. Zollinger H (2003) Color chemistry: synthesis, properties and applications of organic dyes and pigments. Wiley-VCH, Weinheim

4. Merino E, Ribagorda M (2012) Beilstein J Org Chem 8:1071-1090

5. Hamon F, Djedaini-Pilard F, Barbot F, Len C (2009) Tetrahedron 65:10105-10123

6. Emoto A, Uchida E, Fukuda T (2012) Polymers 4:150-186

7. Yamada M, Kondo M, Mamiya J, Yu Y, Kinoshita M, Barrett CJ, Ikeda T (2008) Angew Chem Int Ed 47:4986-4988

8. Baer E, Tosoni AL (1956) J Am Chem Soc 7:2857-2858

9. Firouzabadi H, Mostafavipoor Z (1983) Bull Chem Soc Jpn 56:914-917

10. Orito K, Hatakeyama T, Takeo M, Uchiito S, Tokuda M, Suginome H (1998) Tetrahedron 54:8403-8410

11. Grirrane A, Corma A, García H (2008) Science 322:1661-1664

12. Zhang C, Jiao N (2010) Angew Chem Int Ed 49:6174-6177

13. Cai S, Rong H, Yu X, Liu X, Wang D, He W, Li Y (2013) ACS Catal 3:478-486
14. Hu L, Cao X, Chen L, Zheng J, Lu J, Sun X, Gu H (2012) Chem Commun 48:3445-3447

15. Hu L, Cao X, Shi L, Qi F, Guo Z, Lu J, Gu H (2011) Org Lett 13:5640-5643

16. Kim JH, Park JH, Chung YK, Park KH (2012) Adv Synth Catal 354:2412-2418

17. Corma A, Serna P (2006) Science 313:332-334

18. Zhu H, Ke X, Yang X, Sarina S, Liu H (2010) Angew Chem Int Ed 49:9657-9661

19. Brieger G, Nestrick TJ (1974) Chem Rev 74:567-580

20. Liu X, Ye S, Li HQ, Liu YM, Cao Y, Fan KN (2013) Catal Sci Technol 3:3200-3206

21. Cavani F, Trifiro F, Vaccari A (1991) Catal Today 11:173-301

22. Gaur S, Wu H, Stanley GS, More K, Kumar CSSR, Spivey JJ (2013) Catal Today 208:72-81

23. Aghaei P, Berger RJ (2013) Appl Catal B 132-133:195-203

24. Walther G, Mowbray DJ, Jiang T, Jones G, Jensen S, Quaade UJ, Horch S (2008) J Catal 260:86-92

25. Abad A, Concepcion P, Corma A, Garcia H (2005) Agew Chem Int Ed 44:4046-4049

26. Noujima A, Mitsudome T, Mizugaki T, Jitsukawa K (2011) Kaneda K Molecules 16:8209-8227

27. Shang C, Liu ZP (2011) J Am Chem Soc 133:9938-9947

28. Haber F (1898) Z Elektrochem 4:506-514 